\title{
Blood loss in elective cesarean section: is there a difference related to the type of anesthesia? A randomized prospective study
}

Hüseyin Aksoy¹, Ülkü Aksoy², Burak Yücel ${ }^{3}$, Sezin Saygı Özyurt', Gökhan Açmaz, Mustafa Alparslan Babayiğit ${ }^{5}$, Günhan Gökahmetoğlu ${ }^{6}$, Turgut Aydın ${ }^{3}$

${ }^{1}$ Department of Obstetrics and Gynecology, Kayseri Military Hospital, Kayseri, Turkey

${ }^{2}$ Department of Obstetrics and Gynecology, Kayseri Memorial Hospital, Kayseri, Turkey

${ }^{3}$ Department of Obstetrics and Gynecology, Kayseri Acıbadem Hospital, Kayseri, Turkey

${ }^{4}$ Clinic of Obstetrics and Gynecology, Kayseri Traininig and Research Hospital, Kayseri, Turkey

${ }^{5}$ Department of Public Health and Epidemiology, Gülhane Military Medical Academy, Ankara, Turkey

${ }^{6}$ Clinic of Anesthesiology, Kayseri Traininig and Research Hospital, Kayseri, Turkey

\section{Abstract}

Objective: We aimed to compare the effect of general and spinal anesthesia on maternal blood loss in elective cesarean section (CS).

Material and Methods: This was a prospective randomized study and included 418 healthy pregnant women with a term uncomplicated singleton pregnancy between 37 and 41 weeks of gestation. The study participants were randomly divided into two groups: the general anesthesia group and spinal anesthesia group. CSs were all performed using the same surgical technique, and within the groups, the same anesthetic procedures were used (either general or spinal). The primary outcome for this study was operative blood loss. Hemoglobin and hematocrit concentrations were compared between the two groups.

Results: The preoperative hemoglobin and hematocrit levels were similar in the both groups ( $p=0.08$ and $p=0.239$, respectively). Significantly lower operative blood loss was achieved using spinal anesthesia versus general anesthesia during elective CS. The differences between preoperative and postoperative blood values for both the study groups were statistically significant $(\mathrm{p}<0.001)$.

Conclusion: This study demonstrates that spinal anesthesia is associated with a lower risk of operative blood loss than general anesthesia in low risk patients undergoing elective CS. (J Turk Ger Gynecol Assoc 2015; 16: 158-63)

Keywords: Operative blood loss, cesarean section, anesthesia

Received: 27 February, 2015

Accepted: 29 April, 2015

Available Online Date: 14 July, 2015

\section{Introduction}

Twenty million cesarean sections (CS) are performed worldwide each year $(1,2)$. The CS rates have steadily increased worldwide over the past decades (3-6) Moreover, Turkey has experienced a rapid increase in the rate of CSs. According to data from the Turkish Ministry of Health and National Institute of Statistics, the CS rate per live births increased from $21.2 \%$ in 2003 to $48 \%$ in 2011 . Although the safety of CSs has improved, it is still associated with greater rates of maternal morbidity and mortality than vaginal delivery (7, 8). CS delivery is associated with severe maternal morbidity, including obstetric hemorrhage, hysterectomy, anemia, blood transfusion, and infection (9-11). Among these operative morbidities associated with $\mathrm{CS}$, obstetric hemorrhage is the leading cause of maternal mortality worldwide. Because of both the potential maternal risks and financial concerns, the increase in the cesarean rate is a serious public health problem $(12,13)$.

Anesthesia in pregnant women has always been a concern in obstetric surgery. Anesthesia in CS is of particular concern because it affects millions of women worldwide. Despite substantial improvements in anesthetic and surgical techniques, operative blood loss during CS is still an important medical issue (14).

Therefore, this study aims to compare the effects of general and spinal anesthesia on maternal blood loss among women scheduled for elective CS.

\section{Material and Methods}

This study is a prospective randomized study. It was performed in a tertiary referral hospital between September 2013 and February 2014. The study protocol was approved by 
the local ethics committee of Erciyes University, and informed consent was obtained from each participant. The study population comprised healthy pregnant women who were aged 18-42 years and were scheduled for elective CS. All of the participants had a term uncomplicated singleton pregnancy between 37 and 41 weeks of gestation. In total, 556 healthy [the physical status classification system (ASA) grade I] term (>37 weeks) women scheduled for elective CS delivery under either spinal or general anesthesia were recruited to the study. The preoperative evaluation was consistent with the clinic protocol and included anesthesia counseling and sonographic assessment of the gestational age. The complete blood count and coagulation tests were preoperatively performed. After a preoperative anesthetic evaluation, the patients were randomly divided into two groups: the general anesthesia (GA) and spinal anesthesia (SA) groups. The blood samples for preoperative hemoglobin ( $\mathrm{Hb}$ ) and hematocrit (Htc) concentrations were obtained $1 \mathrm{~h}$ before surgery.

The inclusion criteria for this study were as follows: at least 18 years of age, accepting general or spinal anesthesia for $\mathrm{CS}$, no known previous allergic reaction or sensitivity to any of the anesthetic agents, no medical or surgical conditions requiring special attention, no special request for anesthesia or suspected pathology requiring special anesthesia, and no history of obstetric pathology (such as preeclampsia, hypertensive disorders, polyhydramnios, gestational diabetes mellitus, or abnormal placentation). Our exclusion criteria were as follows: participant refusal, abruptio placentae, placenta previa, Rhesus immunization, fetal compromise or anomaly, maternal coagulation abnormality, thrombocytopenia, abnormal preoperative coagulation test results, sepsis, cord prolapse, spinal deformity, fetal distress syndromes, multiple pregnancy, $<37$ weeks of gestation, known uterine anomaly or fibroid, contraindication to general or regional anesthesia (RA), clinical signs of hypovolemia, antepartum/intrapartum blood transfusion, failed induction of labor, ASA status $\geq \mathrm{II}$, and any systemic diseases or medication that would affect the coagulation system (such as a current or past history of anticoagulant therapy) and patients who failed SA and required conversion to GA. Moreover, patients who had major operative or anesthesia-related complications were excluded from the analysis. The participants were scheduled for $\mathrm{CS}$, and none of the participants received premedication before the operation.

The primary outcome of this study was operative blood loss that was defined as the difference between the preoperative and postoperative $\mathrm{Hb}$ and Htc concentrations. Operative blood loss was calculated as follows: Operative blood loss=preoperative $\mathrm{Hb}$ - postoperative $\mathrm{Hb}$ and preoperative $\mathrm{Htc}$ - postoperative Htc. The same surgeons who were going to perform the operations, informed the participants regarding the procedure. After the participants provided informed written consent, they completed an enrollment questionnaire assessing sociodemographic characteristics and medical information. The medical variables included indication for $\mathrm{CS}$, parity, number of previous CSs, date of last menstrual period, mode of past deliveries, medical course in current pregnancy, and other obstetric and gynecologic history. The final study group comprised 418 subjects. The study participants were randomly assigned into two

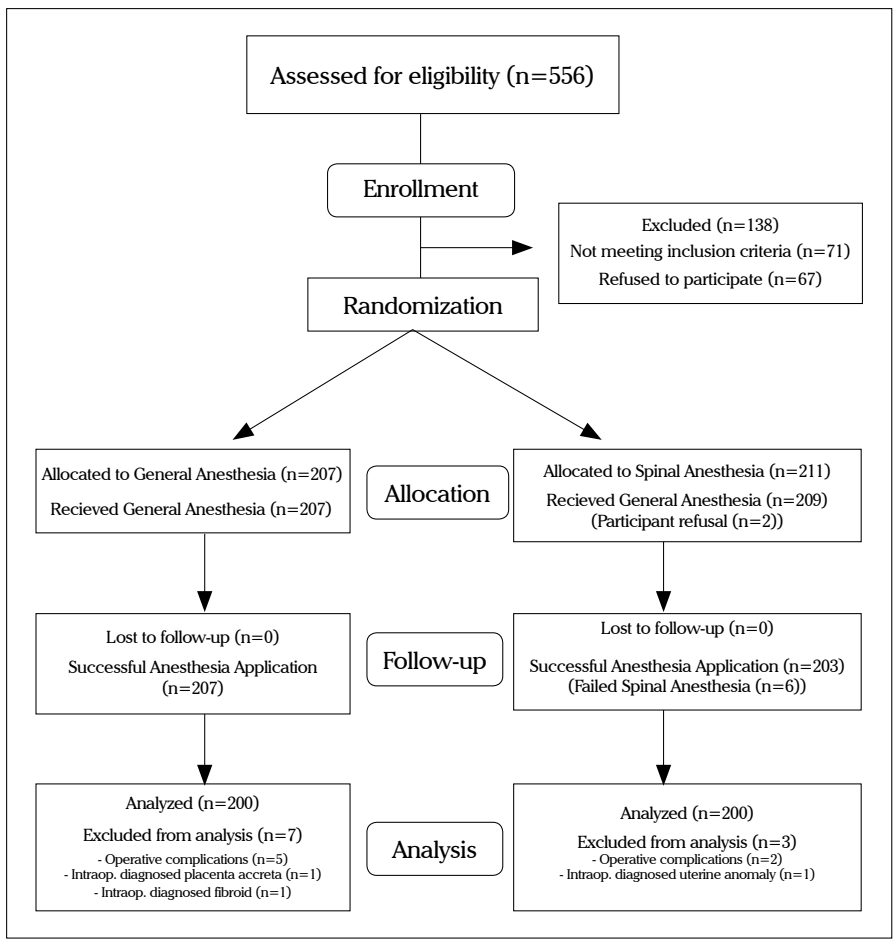

Figure 1. The consort flowchart of study participants

groups: GA or SA. A computer-generated random number chart Statistical Package for the Social Sciences (SPSS) version 20.0 for Windows (SPSS Inc., Chicago, Illinois, United States) was used for the group randomization. As shown in Figure 1, the GA group comprised 207 participants, and the SA group comprised 211 participants.

Each subject underwent a comprehensive obstetric and medical exam as well as an obstetric ultrasound to confirm the placentation and gestational week and to exclude any other pelvic or obstetric pathology (such as leiomyoma or abnormal placentation). All of the participants also underwent comprehensive anesthesia counseling and an anesthetic evaluation.

CSs were performed by two obstetricians, each with $>6$ years of experience, using the same surgical technique, and the surgical details were recorded in a data collection file. The anesthetic was administered by qualified anesthetists with experience in these two anesthetic techniques. The baseline heart rate (HR), noninvasive arterial blood pressure, electrocardiogram (ECG), and arterial oxygen saturation $\left(\mathrm{SpO}_{2}\right)$ were monitored, and the data were recorded prior to anesthesia induction. After anesthesia induction, $\mathrm{ECG}, \mathrm{HR}, \mathrm{SpO}_{2}$, and respiratory rate were continuously monitored, and blood pressure was measured at 2-min intervals. Before spinal anesthesia, all of the SA group patients received $1000 \mathrm{~mL}$ of lactated Ringer solution for preloading. Following preloading, spinal anesthesia was administered at the Lumbal 3-4 or Lumbal 4-5 interspinous level under aseptic technique using a 25-Gauge spinal needle. Hyperbaric bupivacaine $0.5 \%$ 8-10 mg with $20 \mu \mathrm{g}$ fentanyl combined was injected intrathecally over 20 $s$ to achieve a thoracal four sensorial block and then the surgical procedure was allowed to proceed.

In the GA group, GA was induced with $5-7 \mathrm{mg} / \mathrm{kg}$ thiopental and $1 \mathrm{mg} / \mathrm{kg}$ succinylcholine after preoxygenation. After endo- 
tracheal intubation, the patients were ventilated to achieve an end tidal carbon dioxide of 32-35 millimeter of mercury (mmHg), and GA was maintained with $1.5 \%$ sevoflurane in oxygen. After delivery, intravenous administration of $2 \mu \mathrm{g} / \mathrm{kg}$ fentanyl, $0.03 \mathrm{mg} / \mathrm{kg}$ midazolam, and $0.15 \mathrm{mg} / \mathrm{kg}$ rocuronium was initiated, and $1 \%$ sevoflurane in $50 \%$ oxygen $+50 \% \mathrm{~N} 2 \mathrm{O}$ was continued. The anesthesia was discontinued at the end of surgery, and the patients were extubated with a reversal of the drug-induced muscle relaxation.

During surgery, all of the patients were placed in the left lateral supine position to prevent supine hypotension. Immediately following delivery of the infant, slow intravenous bolus dose of 5 international unit (IU) of oxytocin was infused. Additionally, oxytocin infusion (20 IU in $500 \mathrm{~mL} 0.9 \%$ saline over $4 \mathrm{~h}$ ) was administered. If uterine atony or inadequate uterine contractions were detected by the surgeon, supplemental oxytocin was administered. All of the neonates were evaluated by a pediatrician. In case of hypotension, which is defined as a reduction of the mean arterial pressure by $>30 \%$ of baseline, the intravenous (IV) fluid infusion rate was increased. If hypotension persisted despite IV fluid loading, 5-10 mg IV ephedrine was administered. Bradycardia, which is defined as the reduction of $\mathrm{HR}<60$ beats per minute (bpm), was immediately treated by injecting $0.5 \mathrm{mg}$ IV atropine. After surgery, the patients were observed in the recovery room for at least $1 \mathrm{~h}$. The total volume of fluid and all medications administered were recorded. Any blood loss, hypotension, nausea, vomiting, or shivering was also recorded. All of the patients received routine postoperative care. Any postoperative complications were documented. A complete blood count was obtained $12 \mathrm{~h}$ after surgery to determine the $\mathrm{Hb}$ and Htc concentrations. The follow-up visits were scheduled for 1 week after the operation. No additional follow-up appointments were scheduled. All of the procedures were performed by the same surgical team to eliminate other variables.

\section{Statistical analysis}

We planned a study with 220 experimental subjects and 220 control subjects. In a previous study (24), the response within each subject group was normally distributed with a standard deviation of 3.89. If the true difference in the experimental and control means is 2.04 , we will be able to reject the null hypothesis that the population means of the experimental and control groups are equal with probability (power) 1 . The Type I error probability associated with this test of this null hypothesis is 0.05 .

The collected data were analyzed using Statistical Package for Social Sciences software version 17.0 (SPSS Inc., Chicago, IL, United States). The continuous variables were expressed as the mean \pm standard deviation. The Kolmogorov-Smirnov Goodness of Fit test was used to analyze the sample distribution. The Mann-Whitney U and Student's t-test were used to compare the continuous variables. The paired samples t-test was used to compare the preoperative and postoperative measurements. A two-tailed $p$ value $<0.05$ was considered statistically significant.

\section{Results}

In this study, 556 patients were eligible, whereas 138 patients were excluded. Furthermore, 71 patients refused to partici-
Table 1. Some demographic and clinical characteristics of groups

\begin{tabular}{|l|c|c|c|}
\hline & $\begin{array}{c}\text { General anesthesia } \\
(\mathbf{n = 2 0 0 )}\end{array}$ & $\begin{array}{c}\text { Spinal anesthesia } \\
(\mathbf{n = 2 0 0 )}\end{array}$ & $\mathbf{p}$ \\
\hline Age & $26.43 \pm 5.71$ & $26.37 \pm 5.54$ & 0.915 \\
\hline BMI & $27.89 \pm 4.91$ & $27.62 \pm 4.14$ & 0.560 \\
\hline Gravidity & $3.18 \pm 1.41$ & $3.11 \pm 1.32$ & 0.868 \\
\hline Parity & $1.51 \pm 0.90$ & $1.44 \pm 0.84$ & 0.484 \\
\hline Nulliparity & $23(11.5 \%)$ & $27(13.5 \%)$ & NS \\
\hline $\begin{array}{l}\text { Number of } \\
\text { previous CS }\end{array}$ & $1(0-3)$ & $1(0-3)$ & NS \\
\hline
\end{tabular}

Values are expressed as mean \pm standard deviation, median $\left(25^{\text {th }}\right.$ percentile $-75^{\text {th }}$ percentile) or $\mathrm{n}(\%)$ as appropriate.

BMI: body mass index; CS: cesarean section; NS: not significant

Table 2. Distribution of indications for cesarean sections of groups

\begin{tabular}{|l|c|c|}
\hline Indication & $\begin{array}{c}\text { General } \\
\text { anesthesia } \\
(\mathbf{n = 2 0 0 )}\end{array}$ & $\begin{array}{c}\text { Spinal } \\
\text { anesthesia } \\
(\mathbf{n = 2 0 0 )}\end{array}$ \\
\hline Previous cesarean section & $86(43 \%)$ & $83(41.5 \%)$ \\
\hline CPD & $25(12.5 \%)$ & $27(13.5 \%)$ \\
\hline Breech presentation & $19(9.5 \%)$ & $20(10 \%)$ \\
\hline Malpresentation & $17(8.5 \%)$ & $19(9.5 \%)$ \\
\hline Non-reassuring fetal status & $13(6.5 \%)$ & $11(5.5 \%)$ \\
\hline Suspected macrosomia & $11(5.5 \%)$ & $10(5 \%)$ \\
\hline Failed induction & $10(5 \%)$ & $8(4 \%)$ \\
\hline Others & $19(9.5 \%)$ & $22(11 \%)$ \\
\hline CPD: cephalo-pelvic disproportion & \\
\hline
\end{tabular}

pate in the study, and 67 did not meet the inclusion criteria (Figure 1). The final study group included 418 subjects who were randomly divided into two groups. In the GA group, all of the procedures were successfully completed with no complications, and no serious adverse reactions were noted. In six patients in the SA group, SA failed and was converted to GA. These six patients were not included in the analysis. The data of seven patients in the GA group and three in the SA group were also excluded because of intraoperative complications or additional pathological findings. Four hundred patients completed the study, and only data from these 400 patients were used for the analysis.

Mild complications associated with anesthesia, such as nausea, vomiting, shivering, and dizziness, were observed in 12 patients. No severe systemic side effects associated with GA or SA were observed. There was no significant difference between the two groups with respect to the mean patient age, BMI, gravidity, parity, number of nulliparous women or number of previous CSs, as shown in Table 1. The mean age was 26.43 \pm 5.71 years in the GA group and 26.37 \pm 5.54 years in the SA group. Some demographic and clinical characteristics of two study groups are shown in Table 1. The two study groups were similar in terms of indications for CS as shown in Table 2. 
Table 3. Comparisons of groups

\begin{tabular}{|l|c|c|c|}
\hline & $\begin{array}{c}\text { General } \\
\text { anesthesia } \\
(\mathbf{n = 2 0 0 )}\end{array}$ & $\begin{array}{c}\text { Spinal } \\
\text { anesthesia } \\
(\mathbf{n = 2 0 0 )}\end{array}$ & p \\
\hline Preoperative Hb levels & $11.81 \pm 1.39$ & $12.04 \pm 1.21$ & $0.08^{*}$ \\
\hline Postoperative Hb levels & $10.40 \pm 1.39$ & $10.92 \pm 1.24$ & $<0.001 *$ \\
\hline Preoperative Htc levels & $35.87 \pm 4.00$ & $36.31 \pm 3.50$ & $0.239 *$ \\
\hline Postoperative Htc levels & $31.13 \pm 3.89$ & $33.17 \pm 3.47$ & $<0.001 *$ \\
\hline $\begin{array}{l}\text { Difference of Hb } \\
\text { (preoperative- } \\
\text { postoperative) }\end{array}$ & $-1.41 \pm .74$ & $-1.12 \pm .68$ & $<0.001 * *$ \\
\hline $\begin{array}{l}\text { Difference of Htc } \\
\text { (preoperative- } \\
\text { postoperative) }\end{array}$ & $-4.74 \pm 2.16$ & $-3.14 \pm 2.13$ & $<0.001 * *$ \\
\hline $\begin{array}{l}\text { Values are expressed as mean } \pm \text { standard deviation. } \\
\text { *Student's t-test } \\
\text { **Mann Whitney U Test } \\
\text { Hb: hemoglobin (gram/deciliter); Htc: hematocrit (\%) }\end{array}$ \\
\hline
\end{tabular}

The mean preoperative $\mathrm{Hb}$ and $\mathrm{Htc}$ concentrations were $11.81 \pm 1.39$ and $35.87 \pm 4.00$ in the GA group and $12.04 \pm 1.21$ and $36.31 \pm 3.50$ in the SA group, respectively (Table 3 ). There was no significant difference in the preoperative $\mathrm{Hb}$ and $\mathrm{Htc}$ levels between the two study groups $(p=0.08$ and $p=0.239$, respectively). The mean postoperative $\mathrm{Hb}$ and Htc levels were $10.40 \pm 1.39$ and $31.13 \pm 3.89$ in the GA group and $10.92 \pm 1.24$ and $33.17 \pm 3.47$ in the SA group, respectively. The postoperative $\mathrm{Hb}$ and Htc values were significantly lower in the GA group than in the SA group $(p<0.001)$. Thus, significantly lower operative blood loss was achieved using SA during elective CS compared with that using GA.

The mean differences between the preoperative and postoperative $\mathrm{Hb}$ and Htc values in the GA group were $1.41 \pm 0.74$ and $4.74 \pm 2.16$, respectively. The mean differences between the preoperative and postoperative $\mathrm{Hb}$ and Htc values in the SA group were $1.12 \pm 0.68$ and $3.14 \pm 2.13$, respectively. The differences between the preoperative and postoperative blood values for both study groups were statistically significant $(\mathrm{p}<0.001)$ (Figure 2, 3). Four (2\%) patients in the GA group required 9 units of blood transfusion, and two (1\%) patients in the SA group required 4 units.

\section{Discussion}

Several clinical studies have been conducted on the obstetric and non-obstetric risk factors for the high operative blood loss in cesarean delivery. A clinical trial conducted by Al-Zirqi et al. (9), evaluating risk factors of obstetric hemorrhage, concluded that uterine atony is the leading cause of obstetric hemorrhage. Several studies performed by different authors have demonstrated that the factors that prevent normal uterine contraction (such as leiomyoma, polihidramnios, uterine rupture, and prolonged labor), abnormal placentation, maternal blood diseases, antepartum/intrapartum blood transfusion, and hypertensive disorders are risk factors for obstetric blood loss (15-17). Other studies have also confirmed that obstetric risk factors, such

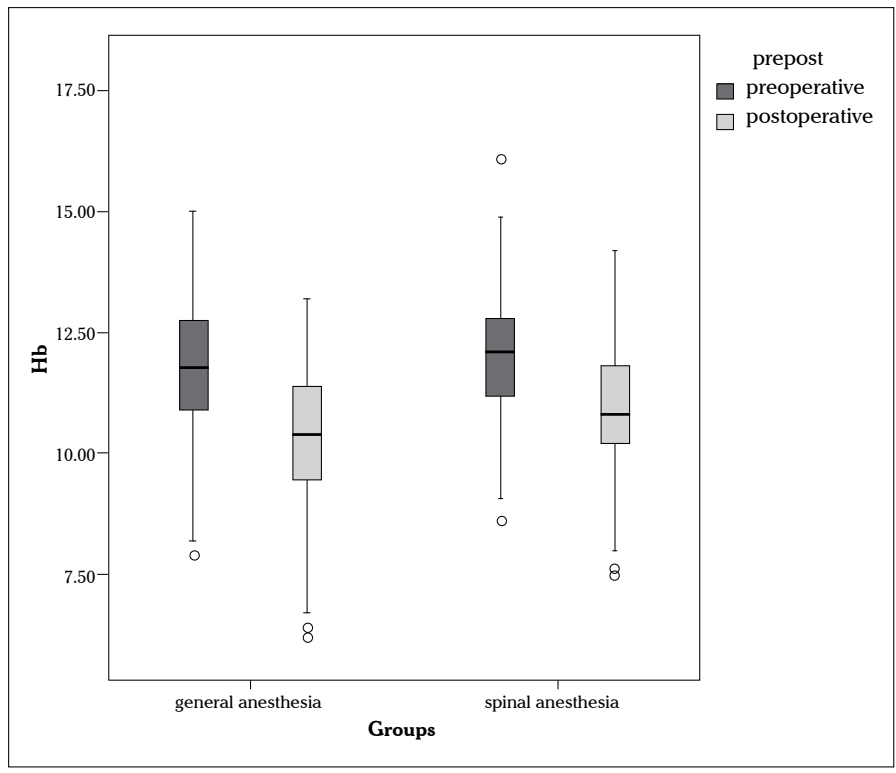

Figure 2. Graphical demonstration of preoperative and postoperative hemoglobin comparisons of groups

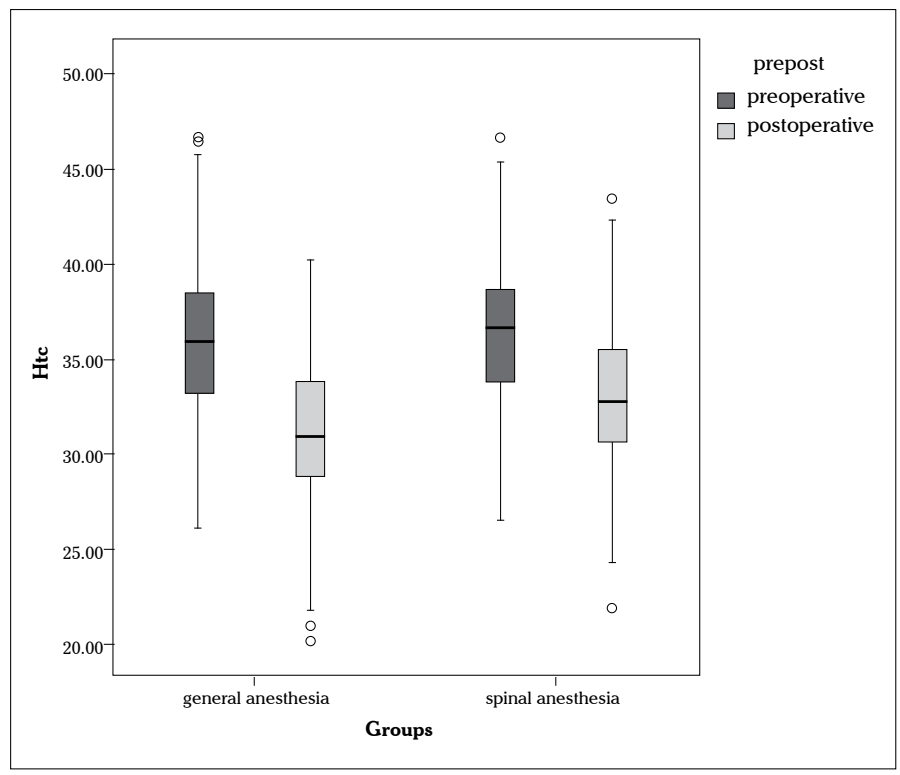

Figure 3. Graphical demonstration of preoperative and postoperative hematocrit comparisons of groups

as parity, gestational age, and fetal macrosomia, contribute to the occurrence of obstetric blood loss (15-17). In 1991, Combs demonstrated that anesthesia is also a risk factor for obstetric hemorrhage (18). It has been reported that adverse uterine contraction and platelet function may be associated with general anesthesia (19).

Obstetric anesthesia has always been a challenging issue for obstetricians and anesthetists. Anesthesia for CS is of particular importance because it affects millions of women worldwide. Both RA and GA are commonly used during cesarean delivery, and both have advantages and disadvantages. In many countries, particularly developed countries, RA is the preferred anesthetic method for CS (20). There are many advantages 
of RA compared with those of GA. Regional anesthetics have been associated with less post-operative pain and less nausea. More importantly, RA reduces the incidence of general anesthetic complications and provides an early bonding between the mother and newborn. However, GA is still commonly used in some countries, primarily because of the greater physician familiarity with it (21-23). Thus, it is important to determine which type of anesthesia is safer for use during CS. To date, only a few studies in the literature have focused on the effect of the type of anesthesia used in CS on obstetric blood loss $(16,24-26)$. The identification of anesthesia-related risk factors may help to develop specific strategies for reducing obstetric blood loss during CS. In general, these studies have focused on the possible link between the anesthesia type and postpartum hemorrhage after cesarean delivery. In a recent large-scale retrospective study, GA was demonstrated to be an independent risk factor for obstetric hemorrhage; patients receiving GA were 8.15 times more likely to experience obstetric hemorrhage than those receiving RA (26). However, the study data were obtained from the Taiwan National Health Insurance Research Dataset, and the diagnoses of obstetric hemorrhage were based on the International Statistical Classification of Diseases and Related Health Problems codes, which were initially designed for billing rather than medical purposes. A systematic review and meta-analysis conducted by Heesen et al. (25), evaluating the effect of general versus RA on estimated blood loss and transfusion requirements after CS, concluded that GA is associated with a greater amount of blood loss than RA. In further analyses, Heesen et al. (25) found a significant difference in the amount of blood loss associated with epidural anesthesia compared with that associated with GA; however, they did not observe a significant difference in the amount of blood loss associated with SA versus GA. The analysis of the well designed, high-quality studies included in this systematic review found no significant increase in the risk of blood transfusions associated with GA. Another systematic review found a significant increase in the risk of blood transfusions with GA; however, this review was based on poorly designed non-randomized studies. Andrews et al. (24) found that GA with halogenated volatile agents was also associated with a greater risk of maternal blood loss compared with RA; however, this study had some limitations, such as an unequal number of patients in the comparison groups, faulty randomization scheme, lack for proper sample size calculations, and lack of allocation concealment. Although reports on operative blood loss during cesarean delivery are primarily based on small heterogeneous groups of patients or during the postpartum period, it is generally widely accepted that blood loss is greater when GA is used instead of RA. However, the higher blood loss associated with GA is of uncertain clinical relevance.

In our study of low-risk patients undergoing elective $\mathrm{CS}$, we found a significantly higher level of blood loss in patients who received GA compared with patients who received SA. Furthermore, more GA patients required blood transfusions than SA patients. Our results are in agreement with Kim et al. (27) and Lertakyamanee et al. (28). Kim et al. (27) retrospectively compared the 287 elective CS patients and concluded that SA is associated with less blood loss during the CS than GA; however, in contrast, they found no significant difference between the two groups with respect to blood loss two days after surgery. The prospective randomized study of Lertakyamanee et al. (28) reported that patients who received GA had significantly increased postoperative blood loss compared with patients who received RA. Our findings are inconsistent with those of Heesen et al. (25) and Yalinkaya et al. (29). Heesen et al. (25) initially concluded that GA was associated with a larger amount of blood loss than RA; however, in a more detailed analysis, they found that compared with GA, there was significantly less blood lost with epidural anesthesia but not with spinal anesthesia. In a prospective trial, including 200 low risk women undergoing CS, Yalınkaya et al. (29) found no significant difference in the operative blood loss between GA and SA groups; however, this study had major limitations, such as the lack of a randomization scheme, proper sample size, and allocation concealment.

In the study by Kim et al. (27), a comparison of the postsurgery and presurgery mean $\mathrm{Hb}$ and Htc levels revealed decreases of $13.5 \%$ and $12.6 \%$, respectively, in the GA group and decreases of $9.9 \%$ and $8.3 \%$, respectively, in the SA group. In our study, the mean $\mathrm{Hb}$ and $\mathrm{Htc}$ concentrations were reduced $11.9 \%$ and $13.2 \%$, respectively, in the GA group and $9.3 \%$ and $8.6 \%$, respectively, in the SA group. The mean differences between the preoperative and postoperative $\mathrm{Hb}$ and Htc values in the study by Yalınkaya et al. (29) were 1.65 and 4.29, respectively, for the GA group and 1.65 and 4.43, respectively, for the SA group. In our study, the mean differences between the preoperative and postoperative $\mathrm{Hb}$ and Htc values were 1.41 and 4.74, respectively, for the GA group and 1.12 and 3.14, respectively, for the SA group (29). The differences we detected in the HB and Htc values for the GA group were similar to those reported by Yalınkaya et al. (29); however, in our study, the mean differences between the preoperative and postoperative $\mathrm{Hb}$ and Htc values in the SA group were lower than those reported by Yalınkaya et al. (29). This discrepancy may be related to the differences in the study protocols and the possible biases in the previous study of Yalınkaya et al. (29).

There are some limitations to our study. The use of a single parameter to determine blood loss is a potential limitation. The inclusion of additional parameters would allow for a more objective assessment of blood loss. However, objective determination of blood loss is very difficult to determine for CSs because of amniotic fluid. Another possible limitation of our study is the lack of an epidural anesthesia (EA) group; the ideal study would include a GA, SA, and EA groups.

CSs have been a long-standing global public health concern $(12,13)$. Obstetric hemorrhage remains a leading cause of maternal morbidity and mortality in both developed and developing countries. Therefore, the prevention of maternal mortality and morbidity due to obstetric hemorrhage will necessarily involve the use of a safe and effective anesthetic technique that causes less bleeding among other life-saving measures. Because of the large number of women who undergo CS each year, strategies designed to reduce CS-related blood loss are of major public health significance. Thus, the effect of different types of anesthesia on obstetric blood loss must be further clarified. In this study, we investigated how anesthesia types 
influence the operative blood loss among women scheduled for elective CS. We hypothesized that women who received GA would have a greater amount of operative blood loss than women who received SA due to adverse uterine contraction and platelet function potentially associated with GA.

In conclusion, our study demonstrated that GA is associated with a higher risk of operative blood loss than SA in low risk patients undergoing elective CS. Although this finding is consistent with several other studies, the clinical relevance of this difference in operative blood loss is unclear. Therefore, there is an obvious requirement for well-designed, large-scale, prospective, randomized, and homogenous studies of all of the anesthetic techniques used in major obstetric surgery and their effect of operative blood loss.

Ethics Committee Approval: Ethics committee approval was received for this study from the Local Institutional ethics committee of Erciyes University.

Informed Consent: Written informed consent was obtained from patients who participated in this study.

Peer-review: Externally peer-reviewed.

Author Contributions: Concept - H.A., U.A., B.Y.; Design - H.A., U.A., B.Y.; Supervision - T.A.; Resource - H.A.; Materials - U.A., S.S.Ö., G.A., G.G.; Data Collection and/or Processing - U.A., S.S.Ö., G.A., G.G.; Analysis and/or Interpretation - M.A.D.; Literature Search - H.A., B.Y.; Writing H.A., B.Y.; Critical Reviews - T.A.

Conflict of Interest: No conflict of interest was declared by the authors.

Financial Disclosure: The authors declared that this study has received no financial support.

\section{References}

1. Betran AP, Merialdi M, Lauer JA, Bing-Shun W, Thomas J, Van LP, Wagner M. Rates of caesarean section: analysis of global, regional and national estimates. Paediatr Perinat Epidemiol 2007; 21: 98-113. [CrossRef]

2. World Health Organization: Facts and Figures from the World Health Report. 2005. Available from: http://www.who.int/whr/2005/ media centre/facts en.pdf.

3. Niino $\bar{Y}$. The increasing cesarean rate globally and what we can do about it. Biosci Trends 2011; 5: 139-50. [CrossRef]

4. Martin JA, Hamilton BE, Sutton PD, Ventura SJ, Mathews TJ, Kirmeyer S, Osterman MJ. Births: final data for 2007. Natl Vital Stat Rep 2010; 58: 1-85.

5. Thomas J, Paranjothy S. Royal College of Obstetricians and Gynaecologists Clinical Effectiveness Support Unit. The National Sentinel Caesarean Section Audit Report. London: RCOG Press; 2001.

6. Cai WW, Marks JS, Chen CH, Zhuang YX, Morris L, Harris JR. Increased cesarean section rates and emerging patterns of health insurance in Shanghai, China. Am J Public Health 1998; 88: 777-80. [CrossRef]

7. Enkin M, Keirse MJNC, Neilson J, Crowther C, Duley L, Hodnett E, Hofmeyr J. A Guide to Effective Care in Pregnancy and Childbirth. 3rd Edition. New York: Oxford University Press; 2000. [CrossRef]

8. Liu S, Liston RM, Joseph KS, Heaman M, Sauve R, Kramer MS, et al. Maternal mortality and severe morbidity associated with lowrisk planned cesarean delivery versus planned vaginal delivery at term. Canadian Medical Association Journal 2007; 176: 455-60. [CrossRef]
9. Al-Zirqi I, Vangen S, Forsen L, Stray-Pedersen B. Prevalence and risk factors of severe obstetric haemorrhage. BJOG 2008; 115: 1265-72. [CrossRef]

10. Mousa HA, Alfirevic Z. Major postpartum hemorrhage: survey of maternity units in the United Kingdom. Acta Obstet Gynecol Scand 2002; 81: 727-30. [CrossRef]

11. Geller SE, Adams MG, Kelly PJ, Kodkany BS, Derman RJ. Postpartum hemorrhage in resource- poor settings. Int J Gynaecol Obstet 2006; 92: 202-11. [CrossRef]

12. Victora CG, Barros FC. Beware: unnecessary caesarean sections may be hazardous. Lancet 2006; 367: 1796-7. [CrossRef]

13. Villar J, Carroli G, Zavaleta N, Donner A, Wojdyla D, Faundes A, et al. Maternal and neonatal individual risks and benefits associated with caesarean delivery: multicentre prospective study. BMJ 2007; 335: 1025. [CrossRef]

14. Devine PC. Obstetric hemorrhage. Semin Perinatol 2009; 33: 76-81. [CrossRef]

15. Sheiner E, Sarid L, Levy A, Seidman DS, Hallak M. Obstetric risk factors and outcome of pregnancies complicated with early postpartum hemorrhage: a population-based study. J Matern Fetal Neonatal Med 2005; 18 : 149-54. [CrossRef]

16. Magann EF, Evans S, Hutchinson M, Collins R, Lanneau G, Morrison. JC. Postpartum hemorrhage after cesarean delivery: an analysis of risk factors. South Med J 2005; 98: 681-5. [CrossRef]

17. Ohkuchi A, Onagawa T, Usui R, Koike T, Hiratsuka M, Izumi A, et al. Effect of maternal age on blood loss during parturition: a retrospective multivariate analysis of 10,053 cases. J Perinat Med 2003; 31: 209-15. [CrossRef]

18. Combs AA, Murphy EL, Laros RK. Factors associated with hemorrhage in cesarean deliveries. Obstet Gynecol 1991; 77: 77-82. [CrossRef]

19. Thorp JM. Clinical aspects of normal and abnormal labor. In: Creasy RK, Resnik R, Iams JD, Lockwood CJ, Moore TR, editors. Creasy and Resnik's Maternal-Fetal Medicine: Principles and Practice. 6th Edition. Philadelphia: Saunders Elsevier; 2009. p. 691-724. [CrossRef]

20. Hibbard BM, Anderson MM, Drife JO, Tighe JR, Gordon G, Willats S. Deaths associated with anaesthesia. In: Rubery E, Bourdillon P, editors. Report on confidential enquiries into maternal deaths in the United Kingdom 1991-1993. Norwich: HMSO; 1996. p. 87-102.

21. Stamer UM, Wiese R, Stüber F, Wulf H, Meuser T. Change in anaesthetic practice for Caesarean section in Germany. Acta Anaesthesiol Scand 2005; 49: 170-6. [CrossRef]

22. Furmanik J. A survey of anaesthesia for caesarean section in Poland. Anestezjol Intens Ter 2010; 42: 65-9.

23. Ajmal M. General anaesthesia for caesarean sections: are anaesthetists dealing with exaggerated fear? European J Anaesthesiol 2011; 28: 815-6. [CrossRef]

24. Andrews WW, Ramin SM, Maberry MC, Shearer V, Black S, Wallace DH. Effect of type of anesthesia on blood loss at elective repeat cesarean section. Am J Perinatol 1992; 9: 197-200. [CrossRef]

25. Heesen M, Hofmann T, Klöhr S, Rossaint R, van de Velde M, Deprest $\mathrm{J}$, Straube $\mathrm{S}$. Is general anaesthesia for caesarean section associated with postpartum haemorrhage? Systematic review and meta-analysis. Acta Anaesthesiol Scand 2013; 57: 1092-102. [CrossRef]

26. Chang CC, Wang IT, Chen YH, Lin HC. Anesthetic management as a risk factor for postpartum hemorrhage after cesarean deliveries. Am J Obstet Gynecol 2011; 205: 462.e1-7. [CrossRef]

27. Kim JE, Lee JH, Kim EJ, Min MW, Ban JS, Lee SG. The effect of type of anesthesia on intra-and postoperative blood loss at elective cesarean section. Korean J Anesthesiol 2012; 62: 125-9. [CrossRef]

28. Lertakyamanee J, Chinachoti T, Tritrakarn T, Muangkasem J, Somboonnanonda A, Kolatat T. Comparison of general and regional anesthesia for cesarean section: success rate, blood loss and satisfaction from a randomized trial. J Med Assoc Thai 1999; 82: 672-80.

29. Yalınkaya A, Güzel AI, Kangal K, Uysal E, Erdem S. Spinal ve genel anestezi uygulanan sezaryen doğumlarında kan değerlerinin karşılaştırılması. Perinatoloji Dergisi 2009; 17: 70-3. 